\title{
Investigation of geographic disparities of pre-diabetes and diabetes in Florida
}

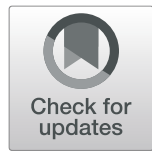

Jennifer Lord ${ }^{1}$, Shamarial Roberson ${ }^{2}$ and Agricola Odoi ${ }^{1^{*}}$

\begin{abstract}
Background: Diabetes is a leading cause of death and disability in the United States, and its precursor, prediabetes, is estimated to occur in one-third of American adults. Understanding the geographic disparities in the distribution of these conditions and identifying high-prevalence areas is critical to guiding control and prevention programs. Therefore, the objective of this study was to investigate clusters of pre-diabetes and diabetes risk in Florida and identify significant predictors of the conditions.

Methods: Data from the 2013 Behavioral Risk Factor Surveillance System were obtained from the Florida Department of Health. Spatial scan statistics were used to identify and locate significant high-prevalence local clusters. The county prevalence proportions of pre-diabetes and diabetes and the identified significant clusters were displayed in maps. Logistic regression was used to identify significant predictors of the two conditions for individuals living within and outside high-prevalence clusters.

Results: The study included a total of 34,186 respondents. The overall prevalence of pre-diabetes and diabetes were 8.2 and $11.5 \%$, respectively. Three significant $(p<0.05)$ local, high-prevalence spatial clusters were detected for pre-diabetes, while five were detected for diabetes. The counties within the high-prevalence clusters had prevalence ratios ranging from 1.29 to 1.85 . There were differences in the predictors of the conditions based on whether respondents lived within or outside high-prevalence clusters. Predictors of both pre-diabetes and diabetes regardless of region or place of residence were obesity/overweight, hypertension, and hypercholesterolemia. Income and physical activity level were significant predictors of diabetes but not pre-diabetes. Arthritis, sex, and marital status were significant predictors of diabetes only among residents of high-prevalence clusters, while educational attainment and smoking were significant predictors of diabetes only among residents of non-cluster counties.

Conclusions: Geographic disparities of pre-diabetes and diabetes exist in Florida. Information from this study is useful for guiding resource allocation and targeting of intervention programs focusing on identified modifiable predictors of pre-diabetes and diabetes so as to reduce health disparities and improve the health of all Floridians.
\end{abstract}

Keywords: Pre-diabetes, Diabetes, Spatial epidemiology, Geographic disparities, Behavioral Risk Factor Surveillance System, Florida, Spatial scan statistics, SaTScan, Logistic regression

\footnotetext{
* Correspondence: aodoi@utk.edu

${ }^{1}$ Department of Biomedical and Diagnostic Sciences, College of Veterinary

Medicine, The University of Tennessee, Knoxville, TN, USA

Full list of author information is available at the end of the article
}

\section{$\triangle B M C$}

(c) The Author(s). 2020 Open Access This article is licensed under a Creative Commons Attribution 4.0 International License, which permits use, sharing, adaptation, distribution and reproduction in any medium or format, as long as you give appropriate credit to the original author(s) and the source, provide a link to the Creative Commons licence, and indicate if changes were made. The images or other third party material in this article are included in the article's Creative Commons licence, unless indicated otherwise in a credit line to the material. If material is not included in the article's Creative Commons licence and your intended use is not permitted by statutory regulation or exceeds the permitted use, you will need to obtain permission directly from the copyright holder. To view a copy of this licence, visit http://creativecommons.org/licenses/by/4.0/ The Creative Commons Public Domain Dedication waiver (http://creativecommons.org/publicdomain/zero/1.0/) applies to the data made available in this article, unless otherwise stated in a credit line to the data. 


\section{Background}

Diabetes and pre-diabetes are defined by fasting plasma glucose (FPG) levels of $126 \mathrm{mg} / \mathrm{dL}$ or higher, and $100 \mathrm{mg} / \mathrm{dL}$ to $<126 \mathrm{mg} / \mathrm{dL}$, respectively [1]. Persons with pre-diabetes have a significantly higher risk of developing diabetes in comparison to those with normal FPG levels. Without early intervention, 70\% of pre-diabetes cases will progress to diabetes within 10 years [2, 3]. Complications of diabetes represent a significant public health burden and can be either: (a) microvascular complications such as neuropathy, nephropathy, and ocular damage; or (b) macrovascular complications such as cardiovascular disease [4-9].

In the United States, there are 30.3 million people with diabetes and 84.1 million with pre-diabetes [10]. Diabetes-related mortality is considered the seventh leading cause of death in the United States [11]. However, a recent study suggests that the contribution of diabetes to national mortality is severely underestimated, and actually approaches $12 \%$ among adults in the United States; this would move its rank to the third leading cause of death, following heart disease and malignant neoplasms $[12,13]$. In the United States, diabetes and related complications are estimated to result in direct medical costs totaling $\$ 237$ billion, and $\$ 90$ billion of indirect costs due to reduced productivity from causes including disability, absenteeism, and early mortality [14].

As of 2016, Florida had 1.9 million people living with diabetes and 1.4 million with pre-diabetes. This was the second-highest (following Texas) number of people with pre-diabetes in any U.S. state [15]. The American Diabetes Association estimates annual diabetes costs in Florida to be $\$ 25$ billion [16]. Moreover, the prevalence of pre-diabetes and diabetes in Florida has been consistently higher than the national average for years [15]. For instance, in 2016 the age-adjusted prevalence estimates of pre-diabetes and diabetes in Florida were 8.7 and $9.8 \%$, respectively, compared to $7.4 \%$ (pre-diabetes) and 9.2\% (diabetes) nationwide [15].

In 2011, the Centers for Disease Control and Prevention (CDC) identified the "diabetes belt", a geographic region with a higher prevalence of diabetes $(11.7 \%)$ than the national average (8.5\%) [17]. The diabetes belt is comprised of a cluster of 644 counties in 15 states, primarily in the Southeastern U.S.: Alabama, Arkansas, Florida, Georgia, Kentucky, Louisiana, Mississippi, North Carolina, Ohio, Pennsylvania, South Carolina, Tennessee, Texas, Virginia, and West Virginia [17]. In these counties, $30 \%$ of the excess risk of diabetes is associated with modifiable, "lifestyle" risk factors and 37\% with non-modifiable, hereditary risk factors [17]. Understanding the geographic distribution of diabetes prevalence is important in guiding resource allocation and intervention programs to combat the problems as it would help in identifying local areas at high risk that would require targeted intervention to reduce disparities. Unfortunately, very few studies have used rigorous spatial epidemiologic/statistical investigations (beyond basic mapping) that would generate useful information to guide targeted health programs. Conducting such studies at sub-state levels will be critically important in providing useful information to help curb this epidemic. Therefore, the objectives of this study were to investigate geographic disparities of pre-diabetes and diabetes prevalence and identify predictors of the two conditions in Florida. These approaches would be critical in helping to meet one of the goals of the Healthy People 2020 which is to reduce health disparities and improve health of the whole population.

\section{Methodology \\ Study area}

This study was performed in the state of Florida, which consists of 67 counties (Fig. 1), many of which are a part of the diabetes belt and have high prevalence proportions of pre-diabetes and diabetes [17]. As of the 2010 population census, Florida had approximately 18.8 million residents, $75 \%$ of whom were white, $16 \%$ were black and $9 \%$ were of other races [20]. Forty nine percent of Florida residents are male while the other $51 \%$ are female [20]. Florida has an even age distribution among adults, with $24 \%$ of the population comprising young adults $18-34$ years old, $26 \%$ are $35-49$ years old, $25 \%$ are $50-64$ years old, and $22 \%$ are seniors ( $\geq 65$ years of age). The state is made up of both urban and rural areas. Miami-Dade County, the southern-most county on the east coast, is the most urban and the most populated, with 2.5 million residents [20]. Liberty County, located to the west of Tallahassee, is the most rural and least populated with a population of 8365 [20]. County land area in Florida ranges from 243.6 mile $^{2}$ (Union County) to 1998 mile $^{2}$ (Collier County) [19].

\section{Pre-diabetes and diabetes data}

Data from the Behavioral Risk Factor Surveillance System (BRFSS) for the period from January to December 2013 were obtained from the Florida Department of Health. Diabetes status was based on self-reports from individual respondents who reported being told by a doctor that they had pre-diabetes or diabetes, not related to pregnancy. No distinction was made between type 1 and 2 diabetes. Data obtained for each respondent included county of residence, age, gender, race, marital status, body mass index (BMI), physical activity level, smoking status, fruit intake, vegetable consumption, hypertension, high cholesterol, arthritis, educational attainment, income level and health insurance. Pre- 


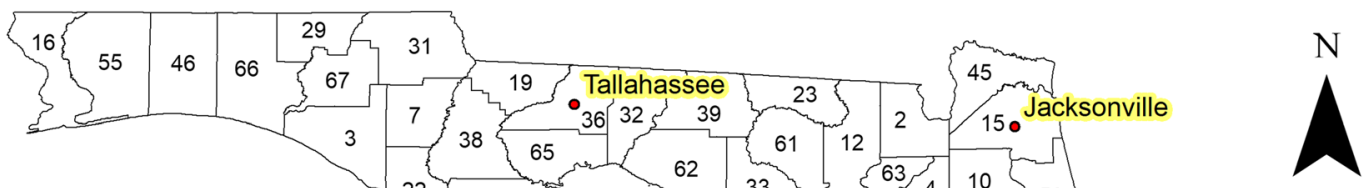

\section{County Numbers and Names}

\begin{tabular}{|c|c|c|c|c|c|c|c|}
\hline 1 & Alachua & 18 & Franklin & 35 & Lee & 52 & Pinellas \\
\hline 2 & Baker & 19 & Gadsden & 36 & Leon & 53 & Polk \\
\hline 3 & Bay & 20 & Gilchrist & 37 & Levy & 54 & Putnam \\
\hline 4 & Bradford & 21 & Glades & 38 & Liberty & 55 & Santa Rosa \\
\hline 5 & Brevard & 22 & Gulf & 39 & Madison & 56 & Sarasota \\
\hline 6 & Broward & 23 & Hamilton & 40 & Manatee & 57 & Seminole \\
\hline 7 & Calhoun & 24 & Hardee & 41 & Marion & 58 & St. Johns \\
\hline & Charlotte & 25 & Hendry & 42 & Martin & 59 & St. Lucie \\
\hline 9 & Citrus & 26 & Hernando & 43 & Miami-Dade & 60 & Sumter \\
\hline 10 & Clay & 27 & Highlands & 44 & Monroe & 61 & Suwannee \\
\hline 11 & Collier & 28 & Hillsborough & 45 & Nassau & 62 & Taylor \\
\hline 12 & Columbia & 29 & Holmes & 46 & Okaloosa & 63 & Union \\
\hline 13 & DeSoto & 30 & Indian River & 47 & Okeechobee & 64 & Volusia \\
\hline 14 & Dixie & 31 & Jackson & 48 & Orange & 65 & Wakulla \\
\hline 15 & Duval & 32 & Jefferson & 49 & Osceola & 66 & Walton \\
\hline 16 & Escambia & 33 & Lafayette & 50 & Palm Beach & 67 & Washington \\
\hline & Flagler & 34 & Lake & 51 & Pasco & & \\
\hline
\end{tabular}
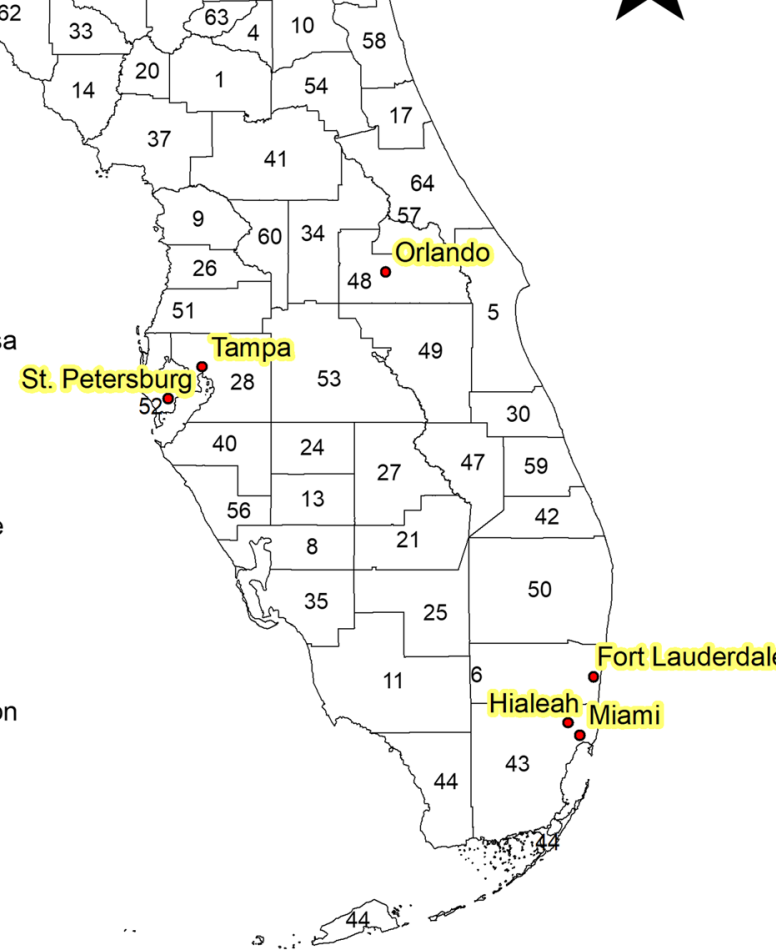

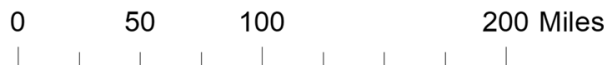

Fig. 1 Geographic distribution of counties and major cities in Florida, USA. The map was created by the authors of the study using ArcGIS software [18]. The geographic boundary file was obtained from the United States Census Bureau TIGER Geodatabase [19]. These files are publicly available, and permission is not required to reproduce the image

diabetes and diabetes data were aggregated to the county level and exported to ArcGIS [18].

\section{Descriptive analyses}

Descriptive analyses were performed in SAS 9.4 [21]. Shapiro-Wilk test was used to assess for normality of distribution of continuous variables. When continuous variables were non-normally distributed, median and interquartile ranges were used for descriptive statistics. Since the data used in this study is from a complex survey, all frequency calculations were done using the survey frequency procedure for complex survey data, PROC SURVEYFREQ, in SAS. This allowed adjustment for strata, clusters and sampling weights.

\section{Cluster identification and investigation}

Kulldorff's spatial scan statistics was used to detect highprevalence spatial clusters of pre-diabetes and diabetes and identify their locations using SaTScan v9.4.2 [22]. Using a Poisson model, the maximum spatial cluster size was set to $13 \%$ of the total study population at risk, based on the most populated county, Miami-Dade, and clusters were identified based on a likelihood ratio test.
For statistical inference, 999 Monte Carlo replications were performed for all analyses, and the null hypothesis of complete spatial randomness was rejected at a $p$-value of $\leq 0.05$. A significant high-prevalence cluster was interpreted as having higher prevalence of pre-diabetes or diabetes within the circular window relative to outside the window. Only clusters with a prevalence ratio $\geq 1.2$ were reported to avoid reporting very low-prevalence clusters.

\section{Logistic regression}

All regression modeling was performed in SAS 9.4 [21] using the survey logistic procedure, PROC SURVEYLOGISTIC, to adjust for the complex sampling strategy used for data collection. The outcomes of interest for regression modeling were binary, reflecting whether a survey respondent reported having prediabetes/diabetes or not. Four logistic models were built: (a) pre-diabetes model for respondents living within high-prevalence clusters, (b) pre-diabetes model for respondents living outside high-prevalence clusters, (c) diabetes model for respondents living within high-prevalence clusters, and (d) diabetes 
model for respondents living outside high-prevalence clusters. Each of the logistic models were built using manual backwards elimination approach using a critical $p$-value of $\leq 0.05$. Non-significant variables were considered potential confounders if their removal from the model resulted in $>20 \%$ change in the coefficients of any of the remaining variables in the model and would be considered for retention in the final model. Biologically meaningful two-way interaction terms of variables included in the final main effects model were assessed for significance with the goal of retaining significant ones in the models. However, none were significant and hence no interaction terms were retained in the final models.

\section{Cartographic displays}

All geographic information system (GIS) manipulations and cartographic displays were performed in ArcGIS [18]. The geographic boundary file used in this study was downloaded from the United States Census Bureau TIGER Geodatabase [19]. Pre-diabetes and diabetes prevalence were displayed in choropleth maps. Predictors of pre-diabetes and diabetes that were found to be significant in the logistic regression models were also displayed in choropleth maps. Critical intervals in the choropleth maps were determined using Jenk's optimization classification scheme. Significant spatial clusters of high pre-diabetes and diabetes prevalence were also displayed using ArcGIS [18].

\section{Results}

\section{Descriptive analyses}

A total of 34,186 respondents participated in the BRFSS survey and were included in the study. The prevalence of diabetes was $11.5 \%$ while that of pre-diabetes was $8.2 \%$ (Table 1). Respondents ranged in age from 18 to 99 years, with a median of 61 and an interquartile range of 48 to 72 . The prevalence of diabetes and pre-diabetes among seniors ( $\geq 65$ years old) was 24.0 and $12.7 \%$, respectively.

County prevalence proportions of pre-diabetes and diabetes are displayed in Fig. 2. Pre-diabetes prevalence ranged from 4.7 to $16.1 \%$, with a mean of $9.1 \%$. Counties within the eastern panhandle tended to have higher prevalence proportions of pre-diabetes than counties in the western panhandle. Franklin and Taylor Counties, two rural counties, had the highest prevalence proportions of pre-diabetes in the panhandle (Figs. 1 and 2). In addition, Baker and Union Counties in northeast Florida, near the Jacksonville metropolitan area, also had high pre-diabetes prevalence (Figs. 1 and 2). There was also a swath of counties with high prevalence proportions extending from northern to central Florida, in a relatively metropolitan part of the state. Low prevalence proportions of pre-diabetes occurred primarily in urban metro areas such as Tampa (Hillsborough County) and Orlando (Orange County), as well as Miami (Broward and Miami-Dade Counties) and many of the southern coastal counties (Figs. 1 and 2).

Diabetes prevalence ranged from 6.2 to $21.9 \%$, with a mean of $12.3 \%$ (Fig. 2). Many counties with high prediabetes prevalence proportions also had high diabetes prevalence proportions; however, the conditions did exhibit slightly different spatial patterns. Four major regions with relatively high diabetes prevalence could be discerned. In the panhandle, this included counties to the west of Tallahassee (Calhoun, Gadsen, Gulf, and Liberty Counties), as well as a swath of rural counties to the east of Tallahassee (Dixie, Lafayette, Levy, Madison, Suwanee and Taylor Counties) (Figs. 1 and 2). High prevalence proportions of diabetes also occurred in central Florida and extended to counties located inland in the south-central part of the state (Hardee, Hendry, Highlands, Osceola, and Polk Counties) (Figs. 1 and 2). Counties with relatively low diabetes prevalence were located within large metropolitan areas such as Jacksonville (Duval and St. Johns County), Miami (Broward and Miami-Dade Counties), Orlando (Orange County), Gainesville (Alachua and Gilchrist Counties), and Tallahassee (Leon County), as well as along the southern Gulf coast (Figs. 1 and 2).

\section{Clusters of pre-diabetes and diabetes}

Based on the results of spatial scan statistics, three significant $(p<0.001)$ pre-diabetes high-prevalence spatial clusters were identified (Table $2 \&$ Fig. 3). The primary pre-diabetes cluster was composed of 13 counties in northern and central Florida to the east of the panhandle. The prevalence ratio (PR) of this cluster was 1.35 , implying that the prevalence of pre-diabetes within the cluster was $35 \%$ higher than the prevalence in counties outside of the cluster. The prevalence proportion of prediabetes in the cluster area was $10.5 \%$ (Table 2). Two secondary pre-diabetes clusters were identified. Cluster 2 $(\mathrm{PR}=1.41, p<0.001)$ included Polk and Hardee counties and was directly adjacent to the south of the primary cluster (i.e. Cluster 1) (Figs. 1 and 3). Cluster 3 (PR = 1.30, $p<0.001$ ) was composed of a single county, Monroe County, located at the southernmost tip of the state (Figs. 1 and 3). Detailed information on the characteristics of adults living within and outside high-prevalence pre-diabetes clusters are shown in Additional file 1.

Five significant high-prevalence spatial clusters of diabetes were identified (Table 2 and Fig. 3). The primary diabetes cluster (Cluster 1) consisted of eight primarily rural counties located in south-central Florida, and was surrounded by the state's largest metropolitan areas: Orlando to the north, Tampa to the west, and Miami to 
Table 1 Demographic, health, and lifestyle characteristics of adults in Florida, 2013

\begin{tabular}{|c|c|c|c|}
\hline Characteristic & Unweighted Frequency & Weighted frequency & $\begin{array}{l}\text { Weighted \% } \\
\text { (95\% Confidence Interval) }\end{array}$ \\
\hline Diabetes status & $n=34,108$ & & \\
\hline Diabetes & 5189 & $1,736,908$ & $11.45(10.75,12.20)$ \\
\hline No diabetes & 28,919 & $13,812,561$ & $88.45(87.80,89.26)$ \\
\hline Pre-diabetes status & $n=28,239$ & & \\
\hline Pre-diabetes & 2983 & $1,052,085$ & $8.23(7.61,8.88)$ \\
\hline No pre-diabetes & 25,256 & $11,929,511$ & $91.77(91.11,92.40)$ \\
\hline BMI $\left(\mathrm{kg} / \mathrm{m}^{2}\right)$ & $n=32,552$ & & \\
\hline Underweight $(<18.5)$ & 720 & 335,135 & $2.27(1.95,2.64)$ \\
\hline Normal (18.5-24.9) & 10,815 & $5,162,640$ & $34.96(33.79,36.15)$ \\
\hline Overweight (25-29.9) & 11,597 & $5,674,964$ & $36.40(35.20,37.61)$ \\
\hline Obese ( $\geq 30$ ) & 9420 & $3,895,148$ & $26.38(25.33,27.44)$ \\
\hline Hypertension & $n=34,074$ & & \\
\hline Yes & 15,684 & $5,374,943$ & $34.59(33.50,35.69)$ \\
\hline No & 18,390 & $10,165,863$ & $65.41(64.31,66.50)$ \\
\hline Hypercholesterolemia & $n=30,216$ & & \\
\hline Yes & 14,445 & $5,087,114$ & $40.33(39.12,41.56)$ \\
\hline No & 15,771 & $7,525,146$ & $59.67(58.44,60.88)$ \\
\hline Arthritis & $n=33,897$ & & \\
\hline Yes & 13,242 & $4,021,502$ & $26.02(25.11,26.94)$ \\
\hline No & 20,655 & $11,436,638$ & $73.98(73.06,74.89)$ \\
\hline Income level & $n=29,171$ & & \\
\hline$<\$ 15,000$ & 4222 & $1,953,171$ & $14.40(13.44,15.43)$ \\
\hline$\$ 15,000-<\$ 25,000$ & 6390 & $2,765,754$ & $20.40(19.35,21.48)$ \\
\hline$\$ 25,000-<\$ 35,000$ & 3798 & $1,686,773$ & $12.44(11.6,13.33)$ \\
\hline$\$ 35,000-<\$ 50,000$ & 4415 & $1,994,956$ & $14.71(13.85,15.62)$ \\
\hline$\geq \$ 50,000$ & 10,346 & $5,158,624$ & $38.04(36.83,39.27)$ \\
\hline Health care coverage & $n=34,003$ & & \\
\hline Yes & 29,145 & $11,943,771$ & $77.14(76.01,78.22)$ \\
\hline No & 4858 & $3,540,245$ & $22.86(21.78,23.99)$ \\
\hline Race & $n=34,186$ & & \\
\hline White non-Hispanic & 27,368 & $9,291,500$ & $59.61(58.40,60.80)$ \\
\hline Black non-Hispanic & 2947 & $2,170,793$ & $13.93(13.01,14.89)$ \\
\hline Other race non-Hispanic & 1353 & 671,077 & $4.31(3.87,4.79)$ \\
\hline Hispanic & 2518 & $3,454,252$ & $22.16(20.96,23.41)$ \\
\hline Age, years & $n=34,186$ & & \\
\hline $18-24$ & 1377 & $1,798,079$ & $11.54(10.64,12.50)$ \\
\hline $25-34$ & 2518 & $2,412,500$ & $15.48(14.55,16.46)$ \\
\hline $35-44$ & 3196 & $2,397,353$ & $15.38(14.48,16.33)$ \\
\hline $45-54$ & 5149 & $2,741,414$ & $17.59(16.68,18.53)$ \\
\hline $55-64$ & 7331 & $2,573,989$ & $16.51(15.70,17.36)$ \\
\hline 65 or older & 14,615 & $3,664,287$ & $23.51(22.74,24.29)$ \\
\hline Sex & $n=34,186$ & & \\
\hline Male & 13,340 & $7,538,722$ & $48.36(47.16,49.57)$ \\
\hline
\end{tabular}


Table 1 Demographic, health, and lifestyle characteristics of adults in Florida, 2013 (Continued)

\begin{tabular}{|c|c|c|c|}
\hline Characteristic & Unweighted Frequency & Weighted frequency & $\begin{array}{l}\text { Weighted \% } \\
\text { (95\% Confidence Interval) }\end{array}$ \\
\hline Female & 20,846 & $8,048,900$ & $51.64(50.43,52.84)$ \\
\hline Physical activity & $n=28,197$ & & \\
\hline Highly Active ( $\geq 300$ min of moderately intense or vigorous equiv./week) & 9688 & $3,730,259$ & $31.38(30.18,32.60)$ \\
\hline Active (150-300 min of moderately intense or vigorous equiv./week) & 4152 & $1,868,360$ & $15.72(14.75,16.73)$ \\
\hline Insufficiently Active (1-149 min of moderately intense exercise/week) & 4245 & $1,968,192$ & $16.55(15.57,17.59)$ \\
\hline Inactive & 10,112 & $4,322,146$ & $36.35(35.03,37.70)$ \\
\hline Education & $n=34,014$ & & \\
\hline$<$ High school & 3380 & $2,322,729$ & $14.96(13.91,16.08)$ \\
\hline High school & 10,630 & $4,676,820$ & $30.15(29.03,31.29)$ \\
\hline Some college & 9853 & $4,835,448$ & $31.18(30.11,32.27)$ \\
\hline College & 10,151 & $3,677,142$ & $23.71(22.85,24.59)$ \\
\hline Marital status & $n=33,917$ & & \\
\hline Married & 16,832 & $7,736,876$ & $50.05(48.86,51.25)$ \\
\hline Never married & 4686 & $4,070,050$ & $26.33(25.18,27.48)$ \\
\hline Separated/divorced/ widowed & 12,399 & $3,650,783$ & $23.62(22.65,24.58)$ \\
\hline Consume vegetable(s) & $n=30,315$ & & \\
\hline$<1$ per day & 5824 & $2,920,634$ & $20.83(19.80,21.90)$ \\
\hline$\geq 1$ per day & 24,491 & $11,098,769$ & $79.17(78.10,80.20)$ \\
\hline Consume fruit(s) & $n=30,978$ & & \\
\hline$<1$ per day & 11,588 & $5,392,612$ & $37.95(36.73,39.17)$ \\
\hline$\geq 1$ per day & 19,390 & $8,818,683$ & $62.05(60.83,63.27)$ \\
\hline Smoked $\geq 100$ cigarettes & $n=33,078$ & & \\
\hline Yes & 16,679 & $6,744,411$ & $45.07(43.88,46.26)$ \\
\hline No & 16,399 & $8,219,768$ & $54.93(53.74,56.12)$ \\
\hline
\end{tabular}

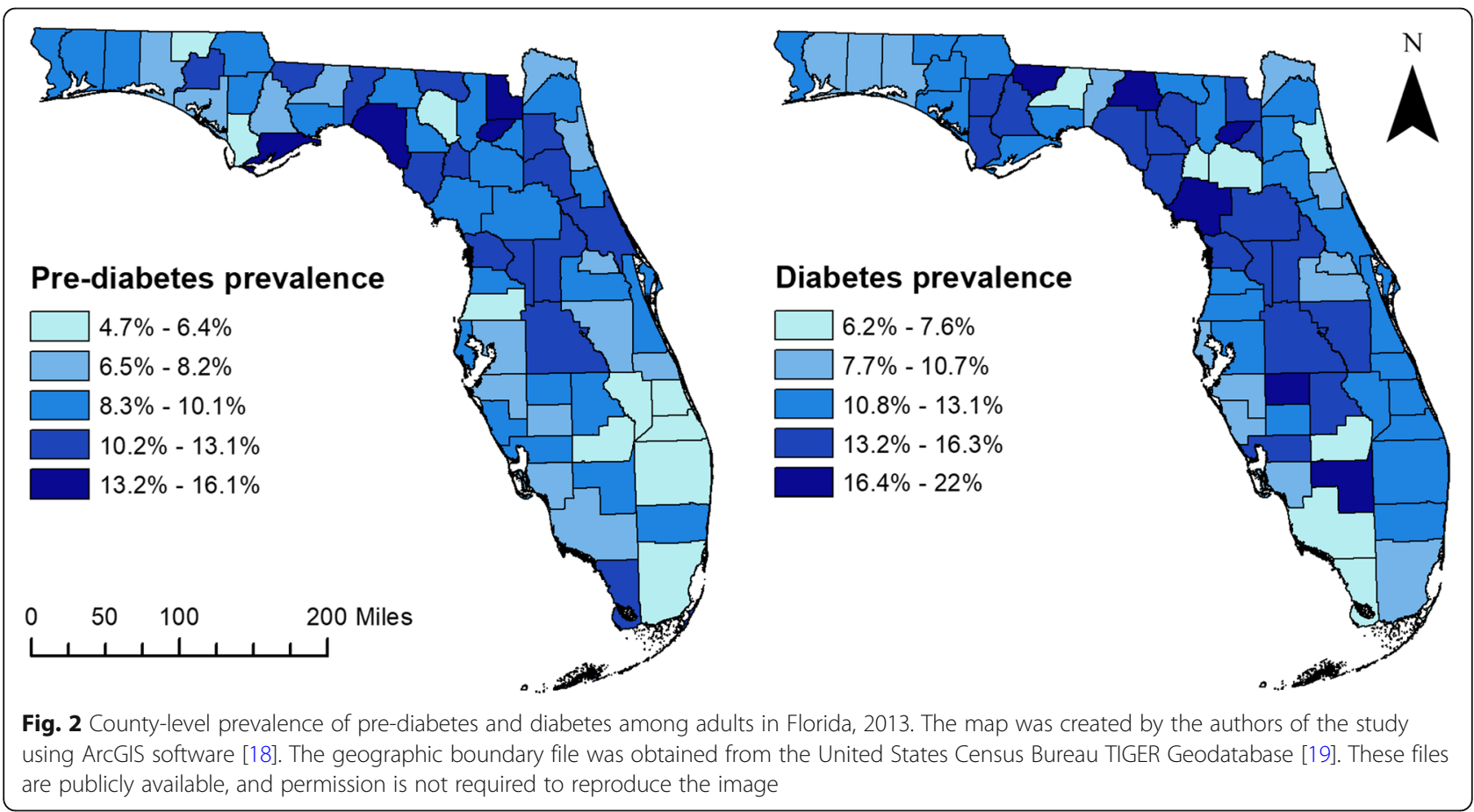


Table 2 Purely spatial significant clusters of pre-diabetes and diabetes among adults in Florida, 2013

\begin{tabular}{|c|c|c|c|c|c|c|}
\hline Cluster & Population & Observed Number of Cases & Expected Number of Cases & Prevalence (\%) & Prevalence Ratio (PR) & $\boldsymbol{p}$-value \\
\hline Pre-diabetes Cluster 1 & $1,562,013$ & 164,158 & $126,592.1$ & 10.5 & 1.35 & $<0.001$ \\
\hline Pre-diabetes Cluster 2 & 401,956 & 45,335 & $32,576.2$ & 11.3 & 1.41 & $<0.001$ \\
\hline Pre-diabetes Cluster 3 & 56,099 & 5885 & 4546.5 & 10.5 & 1.30 & $<0.001$ \\
\hline Diabetes Cluster 1 & $1,003,797$ & 150,890 & $112,126.4$ & 15.0 & 1.38 & $<0.001$ \\
\hline Diabetes Cluster 2 & 884,728 & 129,279 & $98,826.15$ & 14.6 & 1.33 & $<0.001$ \\
\hline Diabetes Cluster 3 & 37,347 & 7704 & 4171.8 & 20.6 & 1.85 & $<0.001$ \\
\hline Diabetes Cluster 4 & 170,874 & 24,458 & $19,087.0$ & 14.3 & 1.29 & $<0.001$ \\
\hline Diabetes Cluster 5 & 35,671 & 6490 & 3984.5 & 18.2 & 1.63 & $<0.001$ \\
\hline
\end{tabular}

the southeast (Figs. 1 and 3). The prevalence of diabetes within this cluster was $38 \%$ higher $(\mathrm{PR}=1.38 ; p<0.001)$ than the prevalence of diabetes in counties outside the cluster. The prevalence proportion of diabetes within the primary cluster was $15 \%$ (Table 2). A secondary highprevalence spatial cluster, Cluster $5(\mathrm{PR}=1.63, p<$ 0.001 ), consisting of a single county (Hendry County) was immediately adjacent to the primary diabetes cluster (Figs. 1 and 3). Two high-prevalence diabetes clusters were also identified in the Florida panhandle. Cluster 3 $(\mathrm{PR}=1.85, p<0.001)$ consisted of a single county, Gadsden County, located to the west of Tallahassee in the central panhandle (Figs. 1 and 3). Cluster 4, located in the eastern panhandle, was composed of eight counties in the most rural region of the state (Figs. 1 and 3). This cluster had 29\% higher prevalence $(\mathrm{PR}=1.29, p<0.001)$ of diabetes than counties outside the cluster. The cluster had an estimated diabetes prevalence of 14.3\% (Table 2
\& Fig. 3). Detailed information on the characteristics of adults living within and outside high-prevalence diabetes clusters are shown in Additional file 2.

\section{Logistic regression results}

Tables 3 and 4 show the results of the final multivariable logistic models. Within both cluster and non-cluster counties, pre-diabetes status was significantly associated with BMI, hypertension, and hypercholesterolemia. Although the strength of association between pre-diabetes and obesity seemed to be greater among residents of non-cluster counties $(\mathrm{OR}=3.89,95 \% \mathrm{CI}: 2.95,5.13)$ in comparison to those living within cluster counties $(\mathrm{OR}=$ $2.67,95 \%$ CI: $1.83,3.90$ ), the ORs were not significantly different since their confidence intervals overlap. However, being overweight was significantly associated with pre-diabetes among those living outside of highprevalence clusters $(\mathrm{OR}=2.12, p<0.001)$, but not among

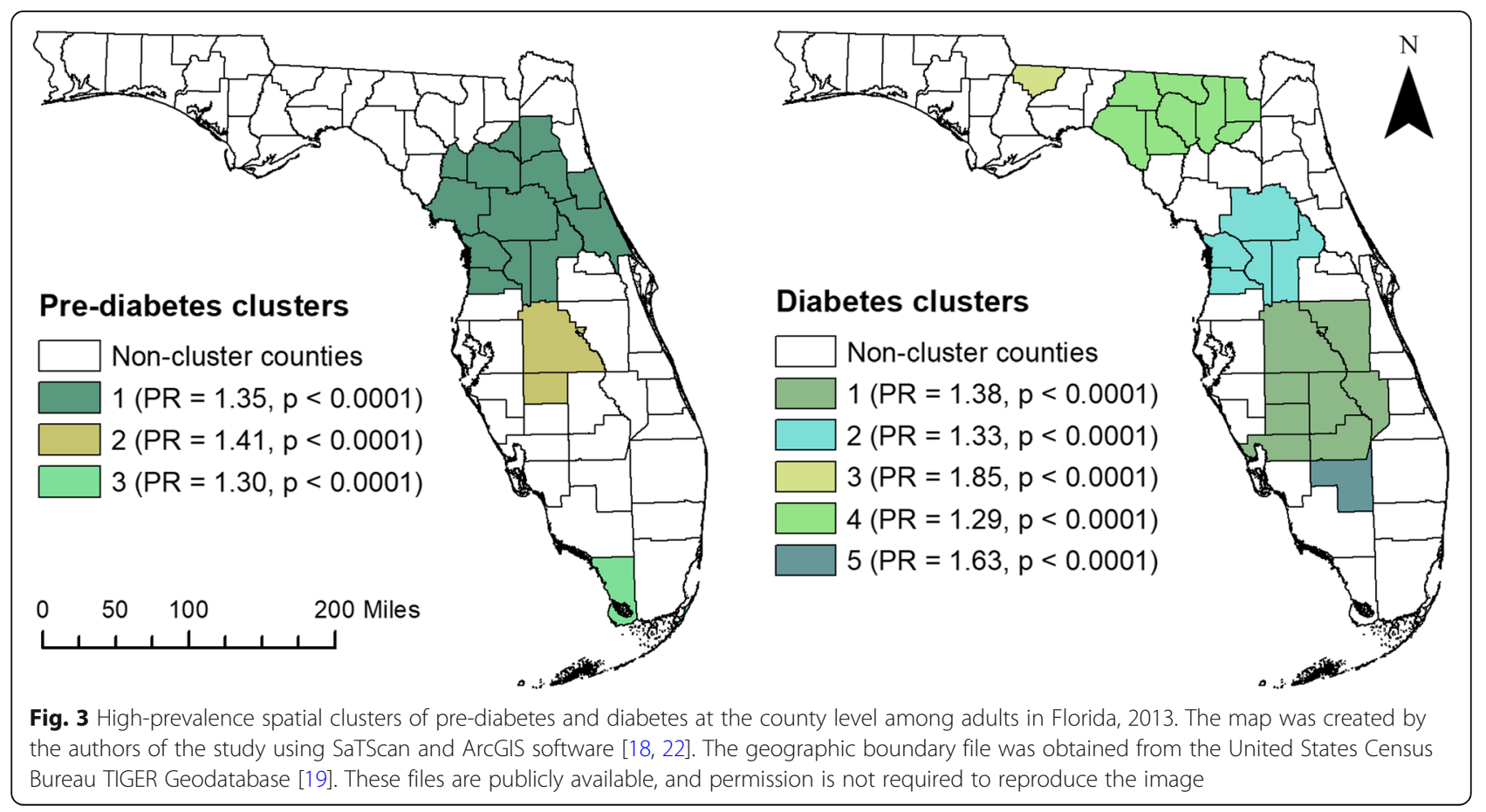


Table 3 Predictors of pre-diabetes among adults residing within and outside high-prevalence clusters in Florida, 2013

\begin{tabular}{|c|c|c|c|c|}
\hline \multirow[t]{2}{*}{ Predictor } & \multicolumn{2}{|c|}{ Model for Cluster Counties } & \multicolumn{2}{|c|}{ Model for Non-cluster Counties } \\
\hline & $\mathrm{OR}^{\mathbf{a}}\left(95 \% \mathrm{Cl}^{\mathbf{b}}\right)$ & $\boldsymbol{p}$-value & $\mathrm{OR}^{\mathbf{a}}\left(95 \% \mathrm{Cl}^{\mathbf{b}}\right)$ & $\boldsymbol{p}$-value \\
\hline \multicolumn{5}{|l|}{ BMI $\left(\mathbf{k g} / \mathrm{m}^{2}\right)$} \\
\hline Obese $(\geq 30)$ & $2.67(1.83,3.90)$ & $<0.001$ & $3.89(2.95,5.13)$ & $<0.001$ \\
\hline Overweight (25-29.9) & $1.27(0.82,1.97)$ & 0.291 & $2.12(1.60,2.82)$ & $<0.001$ \\
\hline Underweight $(<18.5)$ & $1.75(0.56,5.46)$ & 0.332 & $0.91(0.35,2.36)$ & 0.839 \\
\hline Normal (18.5-24.9) & Referent & - & - & - \\
\hline \multicolumn{5}{|l|}{ Hypertension } \\
\hline Yes & $2.37(1.70,3.30)$ & $<0.001$ & $1.80(1.41,2.29)$ & $<0.001$ \\
\hline No & Referent & - & - & - \\
\hline \multicolumn{5}{|l|}{ Hypercholesterolemia } \\
\hline Yes & $2.29(1.62,3.25)$ & $<0.001$ & $1.93(1.52,2.46)$ & $<0.001$ \\
\hline No & Referent & - & - & - \\
\hline \multicolumn{5}{|l|}{ Race } \\
\hline Black, non-Hispanic & $2.40(1.19,4.87)$ & 0.015 & & \\
\hline Hispanic & $0.47(0.28,1.17)$ & 0.127 & - & - \\
\hline Other race, non-Hispanic & $1.76(0.75,4.14)$ & 0.197 & & \\
\hline White, non-Hispanic & Referent & - & & \\
\hline \multicolumn{5}{|l|}{ Age } \\
\hline$\geq 65$ years & - & - & $1.67(1.28,2.18)$ & 0.001 \\
\hline $55-64$ years & & & $1.43(1.06,1.94)$ & 0.020 \\
\hline $18-54$ years & & & Referent & - \\
\hline \multicolumn{5}{|l|}{ Smoking status } \\
\hline$\geq 100$ lifetime cigarettes & $1.49(1.06,2.08)$ & 0.021 & - & - \\
\hline$<100$ lifetime cigarettes & Referent & - & & \\
\hline
\end{tabular}

residents of cluster counties $(\mathrm{OR}=1.27 ; p=0.291)$. On the other hand, although hypertension $(\mathrm{OR}=2.37,95 \%$ CI: $1.70,3.30)$ and hypercholesterolemia $(\mathrm{OR}=2.29,95 \%$ CI: $1.62,3.25)$ seemed to have stronger associations with pre-diabetes within cluster counties in comparison to the rest of the state $\left(\mathrm{OR}_{\text {hypertension }}=1.80,95 \% \mathrm{CI}: 1.41\right.$, 2.29; $\mathrm{OR}_{\text {hypercholesterolemia }}=1.93,95 \% \mathrm{CI}: 1.52,2.46$ ), again these were not significantly different as evidenced by the overlapping confidence intervals of the ORs.

Race and smoking status had significant associations with pre-diabetes status within cluster counties, but not the rest of the state (outside cluster counties). Compared to being white, being non-Hispanic black was associated with higher odds of pre-diabetes $(\mathrm{OR}=$ 2.40, 95\% CI: 1.19, 4.87). Age, however, was a significant predictor of pre-diabetes status only among residents of non-cluster counties. Being 55-64 years $(\mathrm{OR}=1.43,95 \% \mathrm{CI}: 1.06,1.94)$ or $\geq 65$ years of age $(\mathrm{OR}=1.67,95 \% \mathrm{CI}: 1.28,2.18)$ were associated with significantly higher odds of pre-diabetes in comparison to being $18-54$ years of age.
The following variables had statistically significant associations with diabetes status regardless of location: BMI, hypertension, hypercholesterolemia, income, age, and physical activity level. As with the pre-diabetes models, the strength of some of the associations seemed to be higher in non-cluster counties than in cluster counties, however, these differences were not statistically significant. For instance, among non-cluster counties, the strength of association between diabetes and obesity $\left(\mathrm{OR}_{\text {obesity }}=3.68,95 \% \mathrm{CI}: 2.84,4.76\right)$ and overweight $\left(\mathrm{OR}_{\text {overweight }}=2.06,95 \% \mathrm{CI}: 1.56,2.73\right)$ seemed higher had than those in cluster counties $\left(\mathrm{OR}_{\text {obesity }}=2.99,95 \%\right.$ CI: 2.04, 4.40; $\mathrm{OR}_{\text {overweight }}=1.62,95 \%$ CI: $\left.1.09,2.43\right)$ but the ORs were not significantly different on account of their overlapping CIs. Income, on the other hand, had a seemingly stronger association with diabetes within high-prevalence clusters than in non-cluster counties but again, the ORs were not significantly different. Suffice it to say that in areas that were part of the highprevalence cluster having an income of $<\$ 15,000$ was associated with more than 3 times higher odds of diabetes 
Table 4 Predictors of diabetes among adults residing within and outside high-prevalence clusters in Florida, 2013

\begin{tabular}{|c|c|c|c|c|}
\hline \multirow[t]{2}{*}{ Predictor } & \multicolumn{2}{|c|}{ Model for Cluster Counties } & \multicolumn{2}{|c|}{ Model for Non-cluster Counties } \\
\hline & $\overline{O R^{\mathbf{a}}\left(95 \% \mathrm{Cl}^{\mathbf{b}}\right)}$ & $p$-value & $\overline{\mathrm{OR}^{\mathbf{a}}\left(95 \% \mathrm{Cl}^{\mathbf{b}}\right)}$ & $\boldsymbol{p}$-value \\
\hline \multicolumn{5}{|l|}{ BMI $\left(\mathrm{kg} / \mathrm{m}^{2}\right)$} \\
\hline Obese $(\geq 30)$ & $2.99(2.04,4.40)$ & $<0.001$ & $3.68(2.84,4.76)$ & $<0.001$ \\
\hline Overweight (25-29.9) & $1.62(1.09,2.43)$ & 0.019 & $2.06(1.56,2.73)$ & $<0.001$ \\
\hline Underweight $(<18.5)$ & $1.47(0.54,3.99)$ & 0.445 & $0.40(0.18,0.88)$ & 0.024 \\
\hline Normal (18.5-24.9) & Referent & - & Referent & - \\
\hline \multicolumn{5}{|l|}{ Hypertension } \\
\hline Yes & $3.98(2.98,5.33)$ & $<0.001$ & $2.44(1.85,3.23)$ & $<0.001$ \\
\hline No & Referent & - & Referent & - \\
\hline \multicolumn{5}{|l|}{ Hypercholesterolemia } \\
\hline Yes & $1.67(1.27,2.19)$ & $<0.001$ & $1.86(1.45,2.39)$ & $<0.001$ \\
\hline No & Referent & - & Referent & - \\
\hline \multicolumn{5}{|l|}{ Arthritis } \\
\hline Yes & $1.48(1.14,1.93)$ & 0.004 & - & - \\
\hline No & Referent & - & & \\
\hline \multicolumn{5}{|l|}{ Income } \\
\hline$<\$ 15,000$ & $3.34(2.11,5.27)$ & $<0.001$ & $1.63(1.10,2.42)$ & 0.015 \\
\hline$\$ 15,000-<\$ 25,000$ & $1.65(1.16,2.37)$ & 0.006 & $1.51(1.13,2.03)$ & 0.006 \\
\hline$\$ 25,000-<\$ 35,000$ & $1.84(1.22,2.78)$ & 0.004 & $1.36(0.96,1.92)$ & 0.085 \\
\hline$\$ 35,000-<\$ 50,000$ & $1.18(0.78,1.79)$ & 0.442 & $1.10(0.81,1.50)$ & 0.532 \\
\hline$\geq \$ 50,000$ & Referent & - & Referent & - \\
\hline \multicolumn{5}{|l|}{ Age } \\
\hline$\geq 65$ years & $2.20(1.53,3.16)$ & $<0.001$ & $3.14(2.32,4.24)$ & $<0.001$ \\
\hline $55-64$ years & $1.79(1.20,2.68)$ & 0.004 & $2.15(1.55,2.98)$ & $<0.001$ \\
\hline $18-54$ years & Referent & - & Referent & - \\
\hline \multicolumn{5}{|l|}{ Sex } \\
\hline Male & $1.68(1.30,2.19)$ & $<0.001$ & - & - \\
\hline Female & Referent & - & & \\
\hline \multicolumn{5}{|l|}{ Physical activity level } \\
\hline Inactive & $1.47(1.09,1.98)$ & 0.013 & $1.61(1.24,2.08)$ & $<0.001$ \\
\hline $\begin{array}{l}\text { Insufficiently active (1-149 min of moderately } \\
\text { intense exercise/week) }\end{array}$ & $1.64(1.06,2.53)$ & 0.027 & $1.13(0.83,1.55)$ & 0.438 \\
\hline $\begin{array}{l}\text { Active (150-300 min of moderately intense or } \\
\text { vigorous equiv./week) }\end{array}$ & $1.46(0.94,2.28)$ & 0.091 & $1.32(0.95,1.84)$ & 0.102 \\
\hline $\begin{array}{l}\text { Highly active ( } \geq 300 \text { min of moderately intense } \\
\text { or vigorous equiv./week) }\end{array}$ & Referent & - & Referent & - \\
\hline Educational attainment & - & - & & \\
\hline Less than high school & & & $1.76(1.13,2.74)$ & 0.013 \\
\hline High school graduate & & & $0.98(0.75,1.28)$ & 0.883 \\
\hline Some college & & & $0.97(0.75,1.27)$ & 0.845 \\
\hline College graduate & & & Referent & - \\
\hline \multicolumn{5}{|l|}{ Marital status } \\
\hline Married & $2.16(1.28,3.63)$ & 0.004 & - & - \\
\hline Separated, divorced, or widowed & $1.59(0.94,2.70)$ & 0.086 & & \\
\hline Never married & Referent & - & & \\
\hline
\end{tabular}


Table 4 Predictors of diabetes among adults residing within and outside high-prevalence clusters in Florida, 2013 (Continued)

\begin{tabular}{|c|c|c|c|c|}
\hline \multirow[t]{2}{*}{ Predictor } & \multicolumn{2}{|c|}{ Model for Cluster Counties } & \multicolumn{2}{|c|}{ Model for Non-cluster Counties } \\
\hline & $\mathrm{OR}^{\mathbf{a}}\left(95 \% \mathrm{Cl}^{\mathbf{b}}\right)$ & $p$-value & $\mathrm{OR}^{\mathbf{a}}\left(95 \% \mathrm{Cl}^{\mathbf{b}}\right)$ & $\boldsymbol{p}$-value \\
\hline Smoking status & - & - & & \\
\hline$\geq 100$ lifetime cigarettes & & & $1.30(1.03,1.63)$ & 0.025 \\
\hline$<100$ lifetime cigarettes & & & Referent & - \\
\hline
\end{tabular}

${ }^{\text {aOdds ratio }}$

${ }^{\mathrm{b}}$ Confidence interval

$(\mathrm{OR}=3.34,95 \% \mathrm{CI}: 2.11,5.27)$ compared to having an annual income of $\geq \$ 50,000$. However, for respondents that were not part of a high-prevalence diabetes cluster, having an income of $<\$ 15,000$ was associated with 1.6 times higher odds of diabetes $(\mathrm{OR}=1.63,95 \% \mathrm{CI}$ : 1.10 , 2.42) compared to having an annual income of $\geq \$ 50$, 000. Arthritis, sex, and marital status had statistically significant associations with diabetes only among residents of cluster counties, while educational attainment and smoking status were only associated with diabetes among residents of non-cluster counties (Table 4). No biologically meaningful significant interactions were detected. The geographic distributions of the identified significant predictors of pre-diabetes and diabetes are displayed in maps in Fig. 4.

\section{Discussion}

This study investigated county-level geographic disparities and predictors of pre-diabetes and diabetes prevalence reported in the 2013 Florida Behavioral Risk Factor Surveillance System (BRFSS) data. Study findings

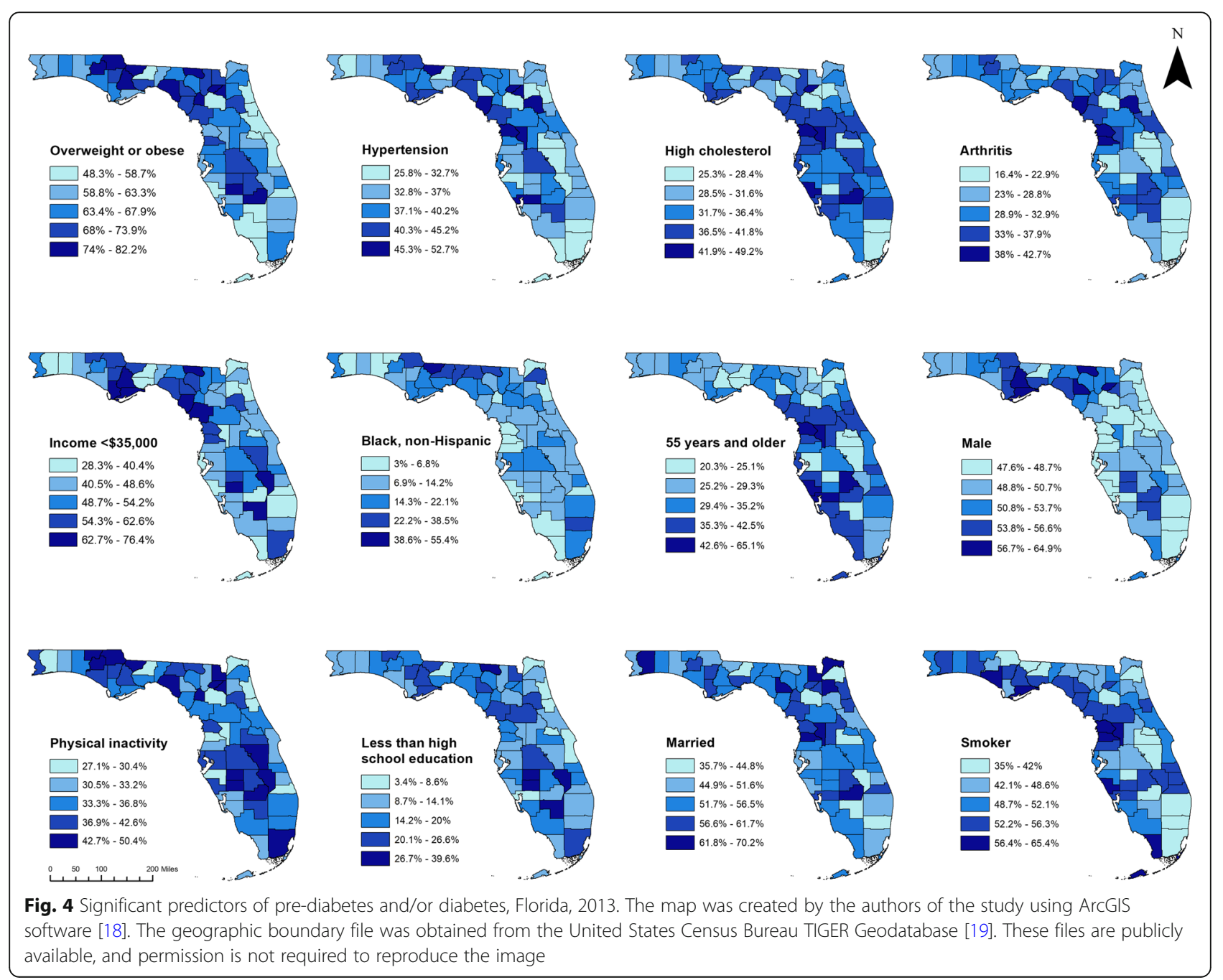


provide information that is useful for guiding resource allocation for prevention and control programs.

\section{Spatial patterns and clusters}

The results of this study indicate that spatial patterns of high prevalence of pre-diabetes and diabetes exist at the county level in Florida. This is consistent with findings from other studies which have reported that counties within the southeastern United States, including Florida, are located in the diabetes belt and have excess risk of diabetes $[17,23]$. The high prevalence in these areas may be attributed, in part, to differences in the distribution of known risk factors, including obesity/overweight, dietary composition, socioeconomic status (SES), and comorbidities such as hypertension and hypercholesterolemia [24-26]. However, other studies have reported the persistence of geographic disparities even after adjusting for variations in these known risk factors [23, 27]. For both conditions, understanding geographic disparities is critical for helping public health officials identify priority areas for intervention, so that areas at high risk may be targeted for implementation of health programs aimed at reducing disease burden.

The major strengths of the spatial scan statistics used to detect and identify high-prevalence clusters are: (a) it does not have the problem of multiple comparisons, and (b) it identifies clusters without prior specification of their suspected location or size, thus eliminating preselection bias. Interestingly, while there was much overlap between counties within high-prevalence prediabetes and diabetes clusters, the distribution of the conditions exhibited somewhat differing spatial patterns. The primary pre-diabetes cluster was large and relatively diverse in terms of urbanization, containing both metropolitan and rural counties, and encompassing the entirety of the secondary diabetes cluster in this region. The primary diabetes cluster, which was composed mainly of rural counties, overlapped with the two counties that comprised a secondary pre-diabetes cluster. A national study found a higher prevalence of diabetes in rural areas compared to urban areas, and that rural residents were less likely to receive diabetes education [28]. Inadequate or lack of public transportation and long distance to healthcare facilities in rural areas may limit access to healthcare services $[29,30]$. Based on Health Resources and Services Administration (HRSA) criteria, three of the eight counties in the primary diabetes cluster, as well as the secondary cluster adjacent to it (Hendry County), are considered geographic Health Professional Shortage Areas (HPSAs), implying that these areas have a shortage of primary care providers [31]. Cluster 4, located in the eastern panhandle, is also mainly comprised of rural counties. Additionally, four of the eight counties within cluster 2 are geographic HPSAs [31].
In addition to influencing accessibility of healthcare services, geographic characteristics can affect health through their impact on food access. Dietary intake is an important part of managing and preventing diabetes, and eating patterns may be influenced by access to healthy food options.

\section{Multivariable logistic regression}

Consistent with findings from other studies [8, 32-37], the results of multivariable logistic regression models from this study showed that hypertension, hypercholesterolemia and overweight/obesity are predictors of both pre-diabetes and diabetes. Previous studies identified geographic and racial disparities in the distribution of these risk factors for diabetes [23, 27]. In addition, results from the current study showed higher odds of diabetes with increasing age, consistent with findings from other studies [34, 35, 37-41]. While increasing age was also a predictor of pre-diabetes status among those living outside of cluster counties, a significant association was not observed within cluster counties.

Within high-prevalence clusters, sex was significantly associated with diabetes, with males having higher odds of diabetes than females. Globally, diabetes prevalence is higher in males (9.1\%) than females (8.4\%), with an estimated 17.1 million more males having diabetes than females. However, sex differences in diabetes prevalence vary by country and age group [42]. This trend is also seen in the United States, where the overall prevalence of diabetes is slightly higher among men $(9.4 \%)$ than women $(9.2 \%)$, with sex differences varying depending on race/ethnicity [10]. Studies of diabetes patients in Europe and the U.S. have shown an inverse relationship between BMI and age in those diagnosed with type 2 diabetes, and that this relationship is affected by sex; at the time of diabetes diagnosis, BMI tends to be lower in men than women $[43,44]$. A comprehensive review on gender and diabetes identified three major contributors to varying insulin sensitivity between men and women: the activity of estrogen, and differences in adipose tissue distribution and adipokine secretion [45].

In the current study, race was significantly associated with pre-diabetes, but this association was only observed among residents of high-prevalence clusters. Similar to these findings, the Reasons for Geographic and Racial Differences in Stroke (REGARDS) study found that prediabetes was more commonly reported among black participants in comparison to white participants [2]. However, in contrast to our findings, the association between race and pre-diabetes among REGARDS participants persisted regardless of region [2].

Although race was associated with pre-diabetes among residents of high-prediabetes clusters in this study, there was no association between race and 
diabetes status. However, disparities across racial and ethnic groups in terms of diabetes prevalence, quality of care, and health outcomes, are among the widespread health inequalities consistently identified in the United States described in the Institute of Medicine report Unequal Treatment [46]. According to CDC estimates, age-adjusted prevalence of diabetes is lowest among non-Hispanic white and Asian populations, and highest among American Indian/Alaska Native and non-Hispanic black populations [10]. Some studies have suggested that observed racial and ethnic diabetes disparities may be a reflection of differences in socioeconomic factors that are associated with race $[47,48]$. For example, the Boston Area Community Health (BACH) survey reported SES as a stronger relative predictor of diabetes risk than race/ethnicity, and found race/ethnicity to be non-significant after the inclusion of additional socioeconomic indicators in a regression model [47]. Another study, using data from the National Health and Nutrition Examination Survey (NHANES), identified interactions between race/ethnicity and other predictors of diabetes risk, namely individual and neighborhood poverty [49]. Regardless of area of residence (high-prevalence cluster areas or non-cluster areas), respondents that were physically inactive had significantly higher odds of diabetes compared to those who were highly active. Interestingly, among those that lived outside highprevalence diabetes clusters, there were no differences in the odds of diabetes between those that were highly active and those that were either insufficiently active or active implying that any level of physical activity among those living outside high-prevalence diabetes cluster might be beneficial. By contrast, among those in high-prevalence diabetes clusters, both being inactive and being insufficiently active had higher odds of diabetes compared to being highly active. However, there was no difference in the odds of diabetes between being highly active and being active among those living in high prevalence clusters. This is an interesting finding that warrants further investigations.

Some studies have shown a gradient of decreased diabetes risk with increasing activity level. For example, a prospective study of Finnish men and women showed a protective effect of increasing physical activity level, a trend that was observed in individuals with both obese and normal BMI [50]. The American Diabetes Association (ADA) recommends that people with diabetes engage in at least $150 \mathrm{~min}$ of moderate-to-vigorous intensity exercise per week, ideally exercising daily and incorporating both aerobic and resistance training [51]. The fact that insufficient physical activity level was associated with higher odds of diabetes within cluster counties highlights the importance of following recommended physical activity guidelines. A growing body of research suggests that physical inactivity itself has detrimental effects on metabolism leading to increased diabetes risk including: insulin resistance, dyslipidemia, and impaired glucose tolerance [52, 53]. Indeed, a U.K. study found higher levels of fasting insulin to be associated with time spent sedentary in a cohort of healthy, middle-aged Caucasian participants, independent of moderate- and vigorous-intensity exercise [54]. Moreover, changing the time spent being sedentary to either light or moderate-to-vigorous intensity physical activity has been shown to increase insulin sensitivity in people with impaired glucose regulation [55]. Thus, the recommendations of the ADA include reducing time spent in sedentary behaviors, and performing light activity at least every 30 min during prolonged sitting [51].

Among residents of cluster counties, increased odds of diabetes were significantly associated with arthritis, a chronic condition with higher prevalence in older age groups [56]. Arthritis has been previously identified as a comorbidity in diabetic patients [57]. Physical inactivity has been associated with arthritis and diabetes in older adults, suggesting that arthritic pain presents a challenge for lifestyle interventions used to prevent and manage diabetes $[58,59]$. The association between arthritis and diabetes did not persist outside of high-prevalence clusters, highlighting the importance of identifying areas with populations at high risk, and investigating predictors of the condition within those populations. Such information is useful in order to inform evidence-based health programming. These findings suggest that residents of high-prevalence clusters, in particular, may benefit from intervention programs which take comorbidities such as arthritis into account, and consider this potential barrier to adhering to recommended physical activity guidelines.

The current study also found a significant association between income level and diabetes. Outside of high-prevalence clusters, educational attainment was also significantly associated with diabetes status. These associations are consistent with evidence in the literature that has established associations between diabetes prevalence and indicators of SES [47, 60-62]. Economic stability and education are two of the social determinants of health established by Healthy People 2020, and are related to reported proximal risk factors for diabetes, including tobacco use, alcohol consumption, and poor dietary quality [9, 63-68]. Interestingly, consumption of fruits or vegetables were not associated with either diabetes or prediabetes in the final model. Cigarette smoking was a 
significant predictor of diabetes status for residents of non-cluster counties. In contrast, it was significantly associated with pre-diabetes status only within highprevalence clusters. The observed differences in predictors of the conditions based on residence within versus outside of cluster counties suggests that the importance of risk factors varies by region, and these may reflect population characteristics. Tailored public health programming based upon these findings may be used to more effectively target those at high risk.

\section{Strengths and limitations}

To our knowledge, this is the first study to explore spatial patterns and clusters of pre-diabetes and diabetes risk in Florida using rigorous spatial epidemiologic methods. Findings from studies using these approaches are useful for health planning purposes to target high-prevalence counties where preventive resources are most needed. This study also demonstrated the usefulness of spatial statistics cluster detection methods, and GIS in identifying areas at highest risk of pre-diabetes and diabetes. Key strengths of the spatial scan statistics used to detect and identify high-prevalence clusters are that it does not have the problem of multiple comparisons and it identifies clusters without prior specification of their suspected location or size, thus eliminating pre-selection bias.

However, this study is not without limitations. The cross-sectional nature of BRFSS limits the ability to draw causal inference. Additionally, use of survey data has inherent problems of potential bias associated with self-reporting for variables such as physical activity and BMI. Self-reports of physical activity have been shown to be influenced by factors such as questionnaire format, gender, and BMI [69, 70]. BRFSS data also do not distinguish between type 1 and type 2 diabetes, two conditions with different pathogenesis and risk factors [42]. However, type 2 diabetes accounts for the vast majority of diabetes, an estimated $90-95 \%$ of the cases in the United States [71]. In addition, the majority of pre-diabetes cases are undiagnosed, and those reported here likely underrepresent the true burden of the condition in the population [10, 72]. Lastly, the logistic regression models built in this study focused on individual-level predictors of diabetes and pre-diabetes status, and did not investigate county-level determinants such as county-level socioeconomic conditions, density of fast-food restaurants and the built environment. Future studies will need to investigate these factors. These limitations, notwithstanding, the findings for this study are important in guiding prevention and control programs.

\section{Conclusions}

This study identified spatial clusters of high pre-diabetes and diabetes prevalence at the county level, indicating existence of geographic disparities. It also identified significant predictors of the two conditions and that the importance of the predictors differed between highprevalence cluster counties and the rest of the state. The study also demonstrated the usefulness of spatial statistics cluster detection methods and GIS in identifying areas at highest risk of pre-diabetes and diabetes. This is useful for guiding resource allocation for prevention and control programs.

\section{Supplementary information}

Supplementary information accompanies this paper at https://doi.org/10. 1186/s12889-020-09311-2.

Additional file 1. Demographic, health, and lifestyle characteristics of adults living within and outside of high-prevalence pre-diabetes clusters in Florida, 2013.

Additional file 2. Demographic, health, and lifestyle characteristics of adults living inside and outside of high-prevalence diabetes clusters in Florida, 2013.

\section{Abbreviations}

BRFSS: Behavioral Risk Factor Surveillance System; SEB: Spatial Empirical Bayes; FPG: Fasting plasma glucose; CDC: Centers for Disease Control and Prevention; BMI: Body mass index; NCHS: National Center for Health Statistics; GIS: Geographic information system; RR: Relative risk; Cl: Confidence interval; OR: Odds ratio; HPSA: Health Professional Shortage Area; HRSA: Health Resources and Services Administration; USDA: United States Department of Agriculture; NHANES: National Health and Nutrition Examination Survey; BACH: Boston Area Community Health; SES: Socioeconomic status;

ADA: American Diabetes Association

\section{Acknowledgements}

We thank the Florida Department of Health for making the data available and the University of Tennessee College of Veterinary Medicine Centers of Excellence for funding the study.

\section{Authors' contributions}

SR was involved in data cleaning and analysis and interpretation of the results. JL was involved in data analysis, manuscript writing and editing. AO was involved in conception of the research idea, guiding data analysis as well as extensive editing of the manuscript. All authors read and approved the final manuscript.

\section{Funding}

This study was supported by funds from University of Tennessee College of Veterinary Medicine Centers of Excellence research funds.

\section{Availability of data and materials}

This data belongs to a third party (Florida Department of Health). The authors do not have the legal authority to share the data. However, it can be requested from the Florida Department of Health by contacting the Director of the Division of Community Health Promotion by mail at 4052 Bald Cypress Way, Mail Bin A13 Tallahassee, FL 32399 or by phone at 850245-4391, or by email at CommunityHealthPromotion@flhealth.gov.

Ethics approval and consent to participate

This study was approved by the University of Tennessee, Knoxville Institutional Review Board (Number: UTK IRB-15-02315-XM). 


\section{Competing interests}

The authors declare that they have no competing interests.

\section{Author details}

'Department of Biomedical and Diagnostic Sciences, College of Veterinary Medicine, The University of Tennessee, Knoxville, TN, USA. ${ }^{2}$ Bureau of Chronic Disease Prevention, Division of Community Health Promotion, Florida Department of Health, Tallahassee, FL, USA.

Received: 21 July 2019 Accepted: 28 July 2020

Published online: 12 August 2020

\section{References}

1. American Diabetes Association. Diagnosing diabetes and learning about prediabetes: american diabetes association ${ }^{\oplus}$ : American Diabetes Association; 2016. Available from: http://www.diabetes.org/diabetes-basics/diagnosis/.

2. Lee LT, Alexandrov AW, Howard VJ, Kabagambe EK, Hess MA, McLain RM, et al. Race, regionality and pre-diabetes in the reasons for geographic and racial differences in stroke (REGARDS) study. Prev Med. 2014;63:43-7 Available from: https://www.sciencedirect.com/science/article/pii/S0091 743514000784.

3. Buysschaert M, Bergman M. Definition of Prediabetes. Med Clin North Am. 2011;95(2):289-97 Available from: https://linkinghub.elsevier.com/retrieve/ pii/S0025712510002026.

4. Buysschaert M, Medina JL, Bergman M, Shah A, Lonier J. Prediabetes and associated disorders. Endocrine. 2015;48(2):371-93. https://doi.org/10.1007/ s12020-014-0436-2.

5. Li C, Ford ES, Zhao G, Tsai J, Balluz LS, Giles WH. Trends of insulin use among US adults with type 2 diabetes: the behavioral risk factor surveillance system, 1995-2007. J Diabetes Complications. 2012;26(1):17-22 Available from: https://www.sciencedirect.com/science/article/abs/pii/S1056 872711001553.

6. Kiani F, Hesabi N, Arbabisarjou A. Assessment of Risk factors in patients with myocardial infarction. Glob J Health Sci. 2015;8(1):255.

7. Tesfaye S. Neuropathy in diabetes. Medicine. 2015;43(1):26-32 Available from: https://www.sciencedirect.com/science/article/pii/S1357303914003041.

8. Qiu M, Shen W, Song $X$, Ju L, Tong W, Wang $H$, et al. Effects of Prediabetes mellitus alone or plus hypertension on subsequent occurrence of cardiovascular disease and Diabetes mellitus. Hypertension. 2015;65(3):52530. https://doi.org/10.1161/HYPERTENSIONAHA.114.04632.

9. Wu Y, Ding $Y$, Tanaka $Y$, Zhang W. Risk factors contributing to type 2 Diabetes and recent advances in the treatment and prevention. Int J Med Sci. 2014;11(11):1185-200 Available from: http://www.medsci.org1185.

10. Centers for Disease Control and Prevention. National Diabetes Statistics Report, 2017. In: Estimates of diabetes and its burden in the United States; 2017.

11. Centers for Disease Control and Prevention. Underlying Cause of Death 1999-2017 on CDC WONDER Online Database. Available from: http://wonder.cdc.gov/ucd-icd10.html. Accessed 12 July 2019.

12. Stokes A, Preston SH. Deaths attributable to diabetes in the united states: comparison of data sources and estimation approaches. PLoS One. 2017; 12(1):e0170219. https://doi.org/10.1371/journal.pone.0170219.

13. Xu J, Murphy SL, Kochanek KD, Bastian B, Arias E. Deaths: Final Data for 2016. In: National Vital Statistics Reports, vol. 67; 2018. Available from: https://www.cdc.gov/.

14. American Diabetes Association AD. Economic Costs of Diabetes in the U.S. in 2017. Diabet Care. 2018;41(5):917-28 Available from: http://www.ncbi.nlm. nih.gov/pubmed/29567642.

15. Centers for Disease Control and Prevention. U.S. Diabetes Surveillance System. 2016. Available from: https://gis.cdc.gov/grasp/diabetes/ DiabetesAtlas.html.

16. American Diabetes Association. The Burden of Diabetes in Florda. 2019. Available from: http://www.diabetes.org/assets/pdfs/advocacy/state-factsheets/florida-state-fact-sheet.pdf.

17. Barker LE, Kirtland KA, Gregg EW, Geiss LS, Thompson TJ. Geographic distribution of diagnosed diabetes in the U.S.: a diabetes belt. Am J Prev Med. 2011:40(4):434-9 Available from: https://www.sciencedirect.com/ science/article/pii/S0749379711000353.

18. Environmental Systems Research Institute (ESRI). ArcGIS Desktop Version 10. 6.1. Environmental Systems Research Institute, Redlands, California, USA; 2017.
19. US Census Bureau. Census TIGER/Line ${ }^{\oplus}$ Shapefiles. 2013.

20. US Census Bureau. American community survey, profile of general population and housing characteristics: 2010 demographic profile data. United States Census Bureau, Suitland, Maryland, USA. 2010. Available from: http://factfinder.census.gov. Accessed 12 July 2019.

21. SAS Institute. SAS Version 9.4. SAS Institute, Cary, NC, USA; 2016.

22. Kulldorff M. Software for the spatial and space-time scan statistics. Silver Spring: Information Management Services, Inc.; 2018.

23. Ford ES, Mokdad AH, Giles WH, Galuska DA, Serdula MK. Geographic variation in the Prevalence of obesity, Diabetes, and obesity-related Behaviors. Obes Res. 2005;13(1):118-22. https://doi.org/10.1038/oby.2005.15.

24. Park S, McGuire LC, Galuska DA. Regional differences in sugar-sweetened beverage intake among US Adults. J Acad Nutr Diet. 2015;115(12):19962002 Available from: https://www.sciencedirect.com/science/article/pii/ S2212267215006619.

25. Oya J, Vistisen D, Christensen DL, Faurholt-Jepsen D, Mohan V, Ramachandran A, et al. Geographic differences in the associations between impaired glucose regulation and cardiovascular risk factors among young adults. Diabet Med. 2015;32(4):497-504. https://doi.org/10.1111/dme.12674.

26. Moody A, Cowley G, Ng Fat L, Mindell JS. Social inequalities in prevalence of diagnosed and undiagnosed diabetes and impaired glucose regulation in participants in the Health Surveys for England series. BMJ Open. 2016;6(2): e010155 Available from: http://www.ncbi.nlm.nih.gov/pubmed/26857106.

27. Voeks JH, McClure LA, Go RC, Prineas RJ, Cushman M, Kissela BM, et al. Regional differences in Diabetes as a possible contributor to the geographic disparity in stroke mortality. Stroke. 2008;39(6):1675-80. https://doi.org/10. 1161/STROKEAHA.107.507053.

28. Krishna S, Gillespie KN, McBride TM. Diabetes burden and access to preventive care in the rural United States. J Rural Health. 2010;26:3-11. https://doi.org/10.1111/j.1748-0361.2009.00259.x.

29. Agency for Healthcare Research and Quality. 2017 National Healthcare Quality and Disparities Report. Rockville; 2017. Available from: www.ahrq. gov/research/findings/nhqrdr/index.html.

30. O'Brien T, Denham SA. Diabetes Care and education in rural regions. Diabet Educ. 2008;34(2):334-47. https://doi.org/10.1177/0145721708316318.

31. Health Resources and Services Administration. HPSA Data Warehouse. Available from: https://data.hrsa.gov/tools/shortage-area. Accessed 12 July 2019.

32. Gray N, Picone G, Sloan F, Yashkin A. Relation between BMI and Diabetes mellitus and its complications among US Older Adults. South Med J. 2015; 108(1):29-36 Available from: http://sma.org/southern-medical-journal/article/ relation-between-bmi-and-diabetes-mellitus-and-its-complications-amongus-older-adults.

33. Sacks FM, Hermans MP, Fioretto P, Valensi P, Davis T, Horton E, et al. Association between plasma triglycerides and high-density lipoprotein cholesterol and microvascular kidney disease and retinopathy in type 2 Diabetes mellitus. Circulation. 2014;129(9):999-1008. https://doi.org/10.1161/ CIRCULATIONAHA.113.002529.

34. Bahijri SM, Jambi HA, Al Raddadi RM, Ferns G, Tuomilehto J. The Prevalence of Diabetes and Prediabetes in the Adult Population of Jeddah, Saudi Arabia- A Community-Based Survey. PLoS One. 2016;11(4):e0152559. https://doi.org/10.1371/journal.pone.0152559.

35. Akhtar S, Khan Z, Rafiq M, Khan A. Prevalence of type II diabetes in district Dir lower in Pakistan. Pakistan J Med Sci. 2016;32(3):622-5 Available from: http://www.ncbi.n/m.nih.gov/pubmed/27375702.

36. Mainous AG, Tanner RJ, Jo A, Anton SD. Prevalence of prediabetes and abdominal obesity among healthy-weight adults: 18-year trend. Ann Fam Med. 2016;14(4):304-10 Available from: http://www.ncbi.nlm.nih.gov/ pubmed/27401417.

37. Shen J, Kondal D, Rubinstein A, Irazola V, Gutierrez L, Miranda JJ, et al. A multiethnic study of pre-Diabetes and Diabetes in LMIC. Glob Heart. 2016; 11(1):61-70 Available from: https://www.sciencedirect.com/science/article/ pii/S2211816015003208.

38. Dubowitz N, Xue W, Long Q, Ownby JG, Olson DE, Barb D, et al. Aging is associated with increased $\mathrm{HbA} 1 \mathrm{c}$ levels, independently of glucose levels and insulin resistance, and also with decreased $\mathrm{HbA} 1 \mathrm{c}$ diagnostic specificity. Diabet Med. 2014;31(8):927-35. https://doi.org/10.1111/dme.12459.

39. Kirkman MS, Briscoe VJ, Clark N, Florez H, Haas LB, Halter JB, et al. Diabetes in older adults. Diabet Care. 2012;35(12):2650-64 Available from: http://www.ncbi.n/m.nih.gov/pubmed/23100048. 
40. Hilawe EH, Chiang C, Yatsuya H, Wang C, Ikerdeu E, Honjo K, et al. Prevalence and predictors of prediabetes and diabetes among adults in Palau: population-based national STEPS survey. Nagoya J Med Sci. 2016; 78(4):475-83 Available from: http://www.ncbi.nlm.nih.gov/pubmed/28008203.

41. Qin Y, Wang R, Ma X, Zhao Y, Lu J, Wu C, et al. Prevalence, awareness, treatment and control of diabetes mellitus - a population based study in Shanghai, China. Int J Environ Res Public Health. 2016;13(5):512 Available from: http://www.mdpi.com/1660-4601/13/5/512.

42. International Diabetes Federation. IDF Diabetes Atlas. 8th ed. Brussels: International Diabetes Federation; 2017.

43. Logue J, Walker JJ, Colhoun HM, Leese GP, Lindsay RS, McKnight JA, et al. Do men develop type 2 diabetes at lower body mass indices than women? Diabetologia. 2011;54(12):3003-6. https://doi.org/10.1007/s00125-011-2313-3.

44. Hillier TA, Pedula KL. Characteristics of an adult population with newly diagnosed type 2 Diabetes: the relation of obesity and age of onset. Diabet Care. 2001;24(9):1522-7 Available from: https://care.diabetesjournals.org/ content/diacare/24/9/1522.full.pdf.

45. Geer EB, Shen W. Gender differences in insulin resistance, body composition, and energy balance. Gend Med. 2009:6(Suppl 1):60-75 Available from: http://www.ncbi.nlm.nih.gov/pubmed/19318219.

46. Institute of Medicine. In: Smedley BD, Stith AY, Nelson AR, editors. Unequal treatment: confronting racial and ethnic disparities in health care. Washington, DC: The National Academies Press; 2003. Available from: http:// www.nap.edu/catalog/12875.html.

47. Link CL, McKinlay JB. Disparities in the prevalence of diabetes: is it race/ ethnicity or socioeconomic status? Results from the Boston Area Community Health (BACH) survey. Ethn Dis. 2009;19(3):288-92 Available from: http://www.ncbi.n/m.nih.gov/pubmed/19769011.

48. Signorello LB, Schlundt DG, Cohen SS, Steinwandel MD, Buchowski MS, Mclaughlin JK, et al. Comparing diabetes prevalence between african americans and whites of similar socioeconomic status. Am J Public Health. 2007:97(12). https://doi.org/10.2105/AJPH.2006.094482.

49. Gaskin DJ, Thorpe RJ, McGinty EE, Bower K, Rohde C, Young JH, et al. Disparities in diabetes: the nexus of race, poverty, and place. Am J Public Health. 2014;104(11):2147-55 Available from: http://www.ncbi.nlm.nih.gov/ pubmed/24228660.

50. Hu G, Lindström J, Valle TT, Eriksson JG, Jousilahti P, Silventoinen K, et al. Physical activity, body mass index, and risk of type 2 diabetes in patients with normal or impaired glucose regulation. Arch Intern Med. 2004;164(8): 892. https://doi.org/10.1001/archinte.164.8.892.

51. Colberg SR, Sigal RJ, Yardley JE, Riddell MC, Dunstan DW, Dempsey PC, et al. Physical Activity/exercise and Diabetes: a position statement of the American Diabetes Association. Diabet Care. 2016;39(11):2065-79 Available from: https://care.diabetesjournals.org/content/39/11/2065.

52. Saunders TJ, Larouche R, Colley RC, Tremblay MS. Acute sedentary behaviour and markers of cardiometabolic risk: a systematic review of intervention studies. J Nutr Metab. 2012;2012 Available from: http://www. ncbi.nlm.nih.gov/pubmed/22754695.

53. Hamilton MT, Hamilton DG, Zderic TW. Sedentary behavior as a mediator of type 2 diabetes. Med Sport Sci. 2014;60:11-26 Available from: http://www. ncbi.nlm.nih.gov/pubmed/25226797.

54. Helmerhorst HJF, Wijndaele K, Brage S, Wareham NJ, Ekelund U. Objectively measured sedentary time may predict insulin resistance independent of moderate- and vigorous-intensity physical activity. Diabetes. 2009;58(8): 1776-9 Available from: http://www.ncbi.nlm.nih.gov/pubmed/19470610.

55. Yates T, Henson J, Edwardson C, Dunstan D, Bodicoat DH, Khunti K, et al. Objectively measured sedentary time and associations with insulin sensitivity: Importance of reallocating sedentary time to physical activity. Prev Med. 2015;76:79-83 Available from: https://pdf.sciencedirectassets. com/272375/1-s2.0-S0091743515X00065/1-s2.0-S0091743515001115/main. pdf?x-amz-security-token=AgoJb3JpZ2luX2VjEAUaCXVzLWVhc3 QtMSJHMEUCIQDth1QBeZ\%252BpW7sfCkMAXuYACB6qEzLq3ya\%252 BCDQvnyy0ZAlgBN\%252F1OHvkKsjyPOOp55Vf7EWaqavnFwbm.

56. Barbour KE, Helmick CG, Boring M, Brady TJ. Vital signs: prevalence of doctor-diagnosed arthritis and arthritis-attributable activity limitation United States, 2013-2015. Morb Mortal Wkly Rep. 2017;66(9):246-53 Available from: http://www.cdc.gov/mmwr/volumes/66/wr/mm6609e1.htm.

57. Gregg EW, Beckles GLA, Williamson DF, Leveille SG, Langlois JA, Engelgau MM, et al. Diabetes and physical disability among older U.S. adults. Diabet Care. 2000;23(9):1272-7 Available from: https://care.diabetesjournals.org/ content/diacare/23/9/1272.full.pdf.
58. Centers for Disease Control and Prevention. Arthritis as a potential barrier to physical activity among adults with diabetes--United States, 2005 and 2007. MMWR Morb Mortal Wkly Rep. 2008;57(18):486-9 Available from: http://www.ncbi.nlm.nih.gov/pubmed/18463606.

59. Cheng YJ, Imperatore G, Caspersen CJ, Gregg EW, Albright AL, Helmick CG. Prevalence of diagnosed arthritis and arthritis-attributable activity limitation among adults with and without diagnosed diabetes: united states, 20082010. Diabet Care. 2012;35:1686-91 Available from: https://care. diabetesjournals.org/content/diacare/35/8/1686.full.pdf.

60. Robbins JM, Vaccarino V, Zhang H, Kasl SV. Socioeconomic status and diagnosed diabetes incidence. Diabet Res Clin Pract. 2005;68(3):230-6 Available from: https://www.sciencedirect.com/science/article/pii/S0168822 704003018.

61. Kanjilal S, Gregg EW, Cheng YJ, Zhang P, Nelson DE, Mensah G, et al. Socioeconomic status and trends in disparities in 4 major risk factors for cardiovascular disease among us adults, 1971-2002. Arch Intern Med. 2006; 166(21):2348. https://doi.org/10.1001/archinte.166.21.2348.

62. Dinca-Panaitescu S, Dinca-Panaitescu M, Bryant T, Daiski I, Pilkington B, Raphael D. Diabetes prevalence and income: results of the Canadian community health survey. Health Policy. 2011;99(2):116-23.

63. Office of Disease Prevention and Health Promotion. Healthy people 2020: social determinants of health. 2019. Available from: https://www. healthypeople.gov/2020/topics-objectives/topic/social-determinants-ofhealth.

64. Barbeau EM, Krieger N, Soobader MJ. Working class matters: socioeconomic disadvantage, race/ethnicity, gender, and smoking in nhis 2000. Am J Public Health. 2004;94(2):269-78. [cited 2019 Apr 5]. https://doi.org/10.2105/AJPH. 94.2.269.

65. Cullmann M, Hilding A, Östenson C-G. Alcohol consumption and risk of prediabetes and type 2 diabetes development in a Swedish population. Diabet Med. 2012:29(4):441-52. https://doi.org/10.1111/j.1464-5491.2011.03450.x.

66. Group TDPPR. The diabetes prevention program: baseline characteristics of the randomized cohort. the diabetes prevention program research group. Diabet Care. 2000;23(11):1619-29 Available from: http://www.ncbi.nlm.nih. gov/pubmed/11092283.

67. Little M, Humphries S, Patel K, Dodd W, Dewey C. Factors associated with glucose tolerance, pre-diabetes, and type 2 diabetes in a rural community of south India: a cross-sectional study. Diabetol Metab Syndr. 2016;8(1):21 Available from: http://www.dmsjournal.com/content/8/1/21.

68. Karter AJ, Stevens MR, Brown AF, Duru OK, Gregg EW, Gary TL, et al. Educational disparities in health behaviors among patients with diabetes: the translating research into action for Diabetes (TRIAD) study. BMC Public Health. 2007;7(1):1-9.

69. Warner ET, Wolin KY, Duncan DT, Heil DP, Askew S, Bennett GG. Differential accuracy of physical activity self-report by body mass index. Am J Health Behav. 2012;36(2):168-78 Available from: http://www.ncbi.n/m.nih.gov/ pubmed/22370255.

70. Prince SA, Adamo KB, Hamel M, Hardt J, Connor Gorber S, Tremblay M. A comparison of direct versus self-report measures for assessing physical activity in adults: a systematic review. Int J Behav Nutr Phys Act. 2008;5(1): 56. https://doi.org/10.1186/1479-5868-5-56.

71. Centers for Disease Control and Prevention. Type 2 Diabetes. 2018. Available from: https://www.cdc.gov/diabetes/basics/type2.html.

72. Geiss LS, James C, Gregg EW, Albright A, Williamson DF, Cowie CC. Diabetes risk reduction behaviors among u.s. adults with prediabetes. Am J Prev Med. 2010;38(4):403-9 Available from: http://www.ncbi.nlm.nih.gov/ pubmed/20307809.

\section{Publisher's Note}

Springer Nature remains neutral with regard to jurisdictional claims in published maps and institutional affiliations. 